Supplement of Clim. Past, 13, 919-942, 2017

https://doi.org/10.5194/cp-13-919-2017-supplement

(c) Author(s) 2017. This work is distributed under

the Creative Commons Attribution 3.0 License.

(c) (1)

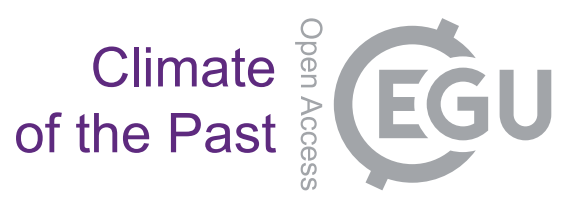

Supplement of

\title{
Regional and global climate for the mid-Pliocene using the University of Toronto version of CCSM4 and PlioMIP2 boundary conditions
}

Deepak Chandan and W. Richard Peltier

Correspondence to: Deepak Chandan (dchandan@atmosp.physics.utoronto.ca)

The copyright of individual parts of the supplement might differ from the CC BY 3.0 License. 


\section{Supplementary Material}

Chandan and Peltier, 2017, Climate of the Past

\section{POP1 profile of diapycnal diffusivity}

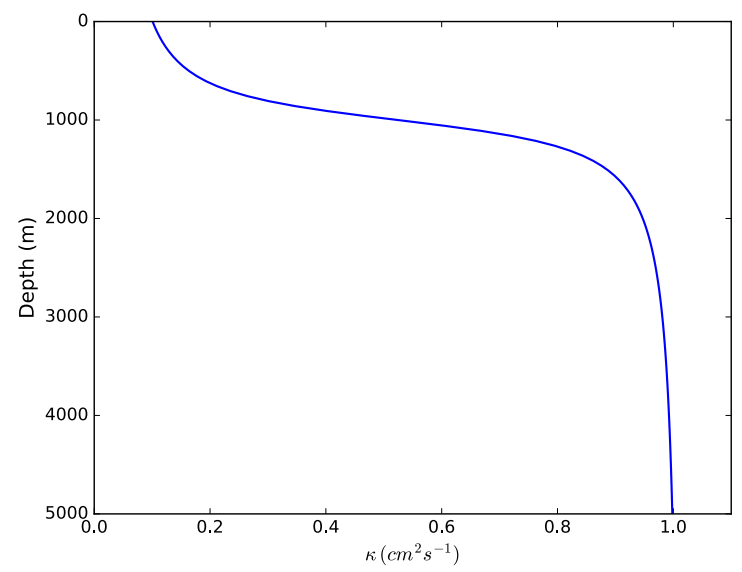

Figure S1. Depth-dependent profile of the diapycnal diffusivity $(\kappa)$ that was used in the ocean component, POP1, of the CCSM3 model and which has been used in our POP1-variant simulations presented in the main text.

\section{Spin-up of Pre-existing Control}

Here we present the spin up diagnostics for several atmospheric, oceanic and sea ice variables in the pre-existing $\mathrm{PI}$ control cesmpifv1mts. 


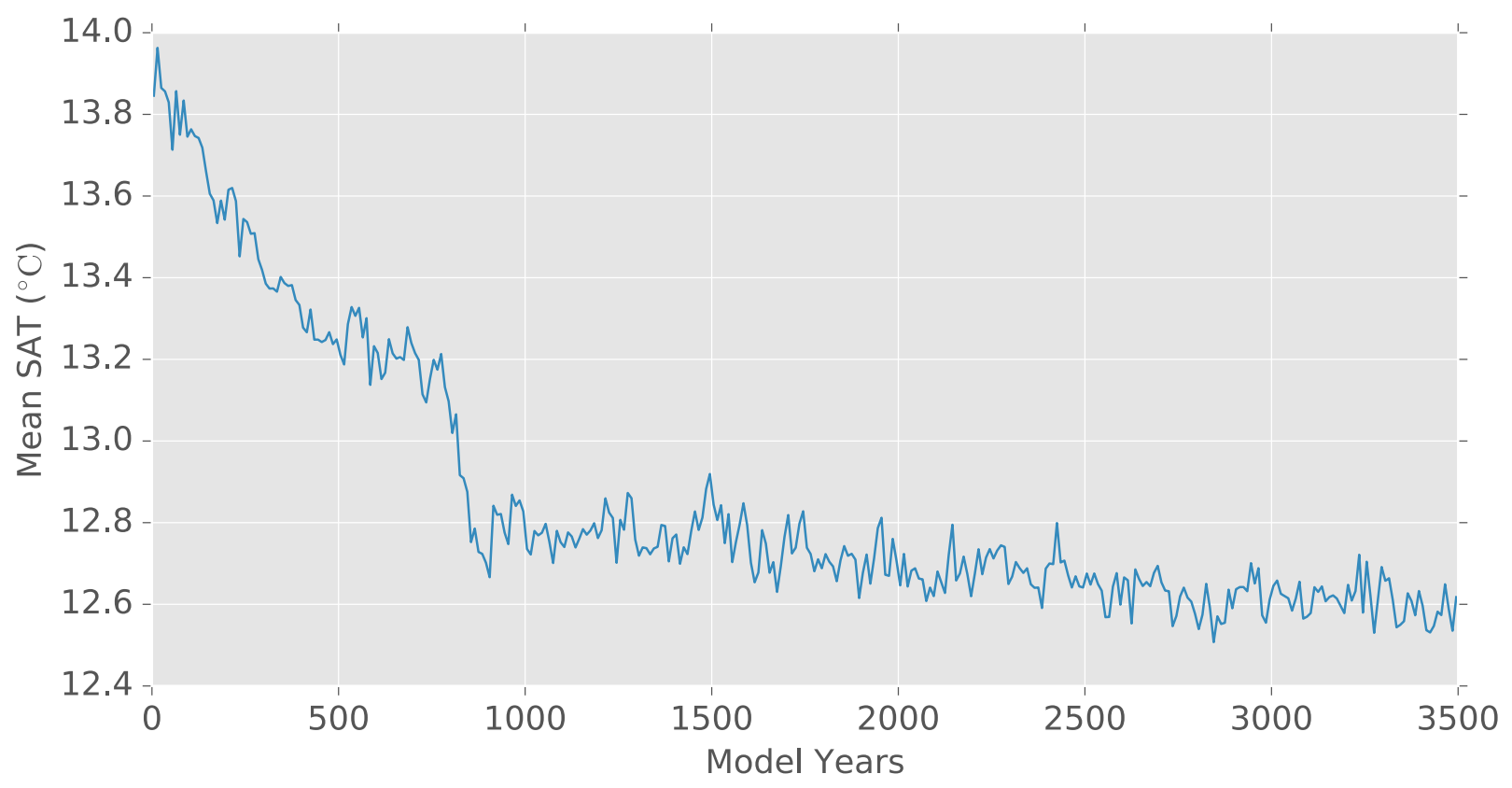

Figure S2. Decadal average of the mean surface air temperature $(2 \mathrm{~m}$ air temperature) in the cesmpifv $1 \mathrm{mts} \mathrm{PI}$-control simulation from which $E^{280}$ and $E^{400}$ were initialized.
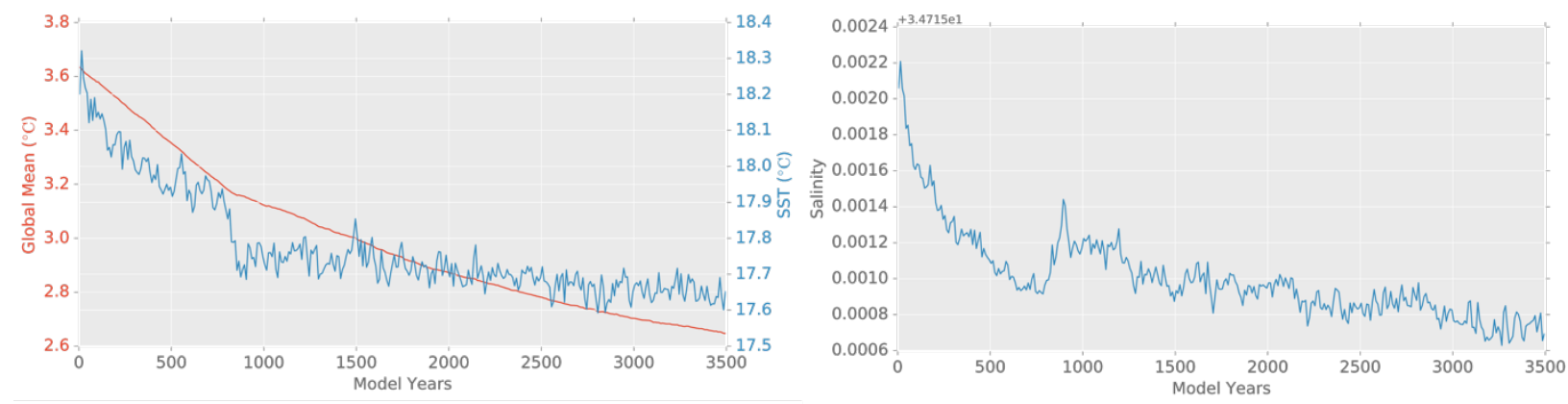

Figure S3. Decadal average of the global mean sea surface temperature and global mean ocean temperature (left) and salinity (right) in the cesmpifv1mts PIcontrol simulation from which $E^{280}$ and $E^{400}$ were initialized. Over the last 500 years of this simulation, the global ocean temperature had a trend of just $0.01^{\circ} \mathrm{C} /$ Century. 


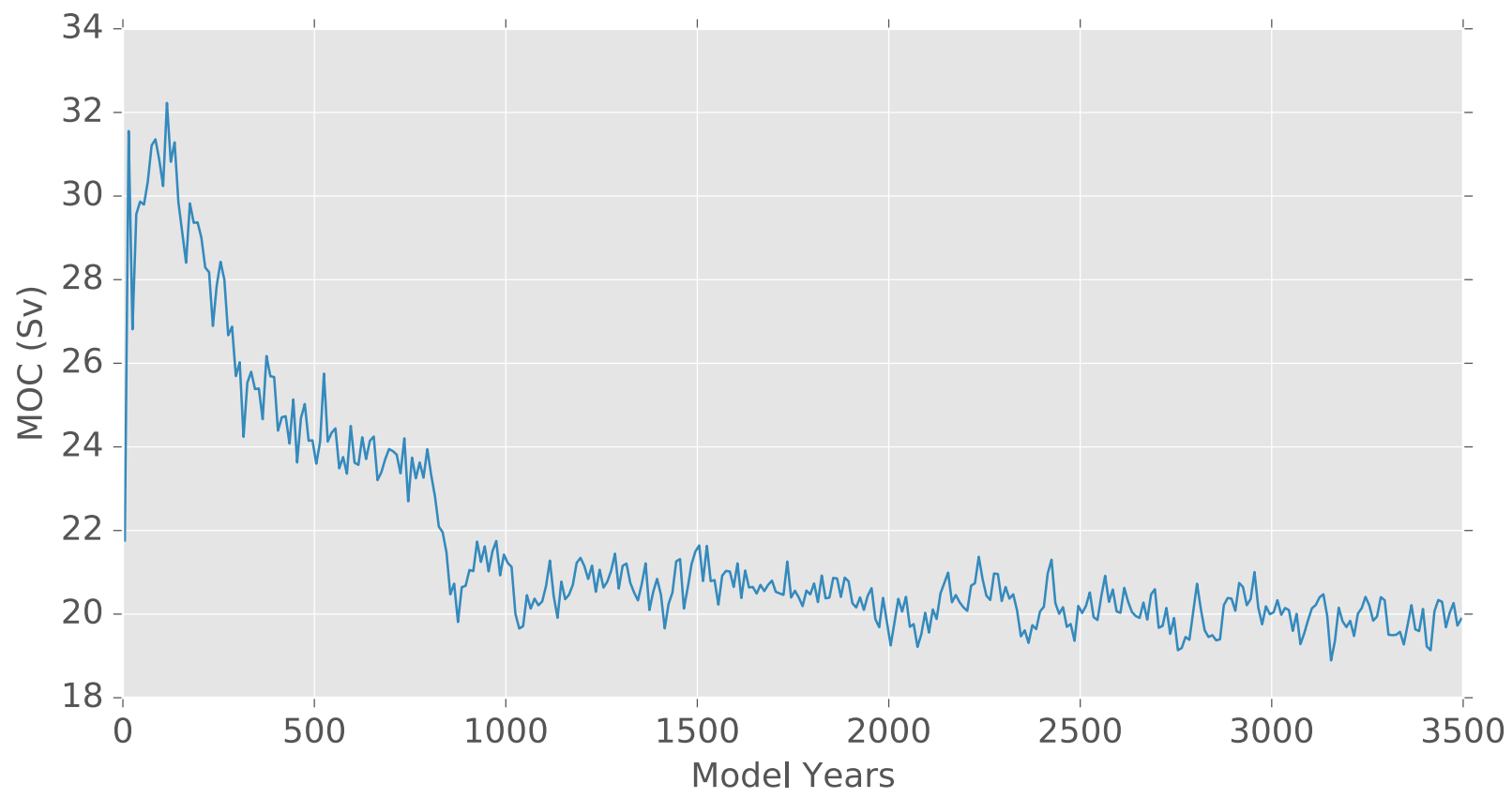

Figure S4. Decadal average of the maximum Atlantic MOC in the cesmpifv1mts PIcontrol simulation from which $E^{280}$ and $E^{400}$ were initialized.
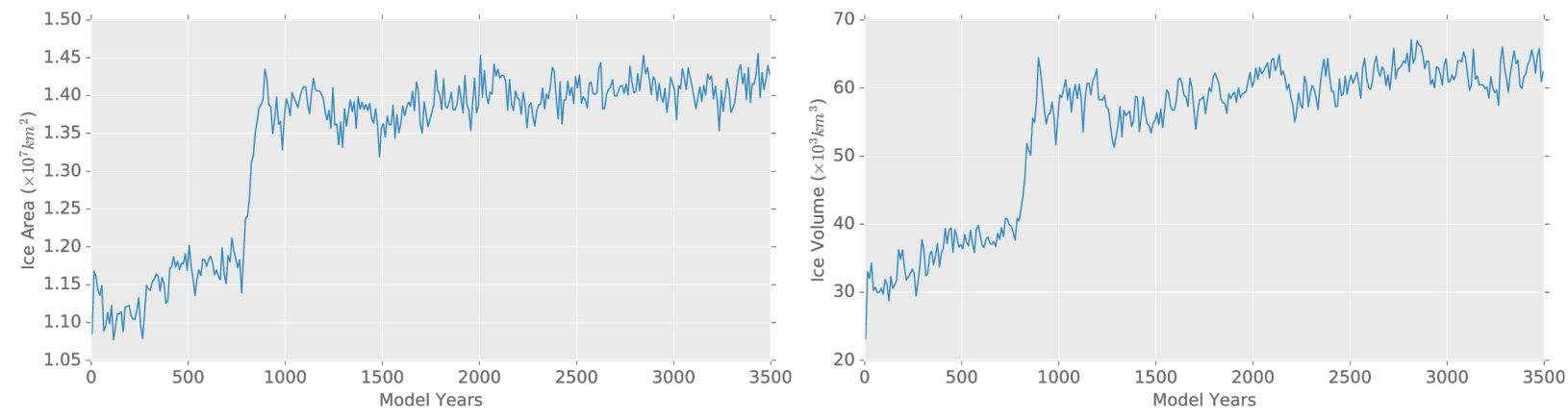

Figure S5. Decadal averages of the Arctic sea ice area and volume in the cesmpifv $1 \mathrm{mts} \mathrm{PI}$-control simulation from which $E^{280}$ and $E^{400}$ were initialized. 


\section{PI Control's comparison to HadISST}

Here we compare the SST and sea ice concentration in our PI-control $E^{280} P$ to that which has been reconstructed for the HadISST dataset [Rayner et al. 2003]. In the context of this comparison if needs to be remembered that the observational data that has gone into the HadISST reconstructions for the late $19^{\text {th }}$ century is very limited, and of lower quality compared to those from the late $20^{\text {th }}$ century onwards. This is particularly the case for sea ice data from this time, which is much more limited than SST data, due to the limited number of ship based journeys that took place close to the polar regions, especially near the South Pole.

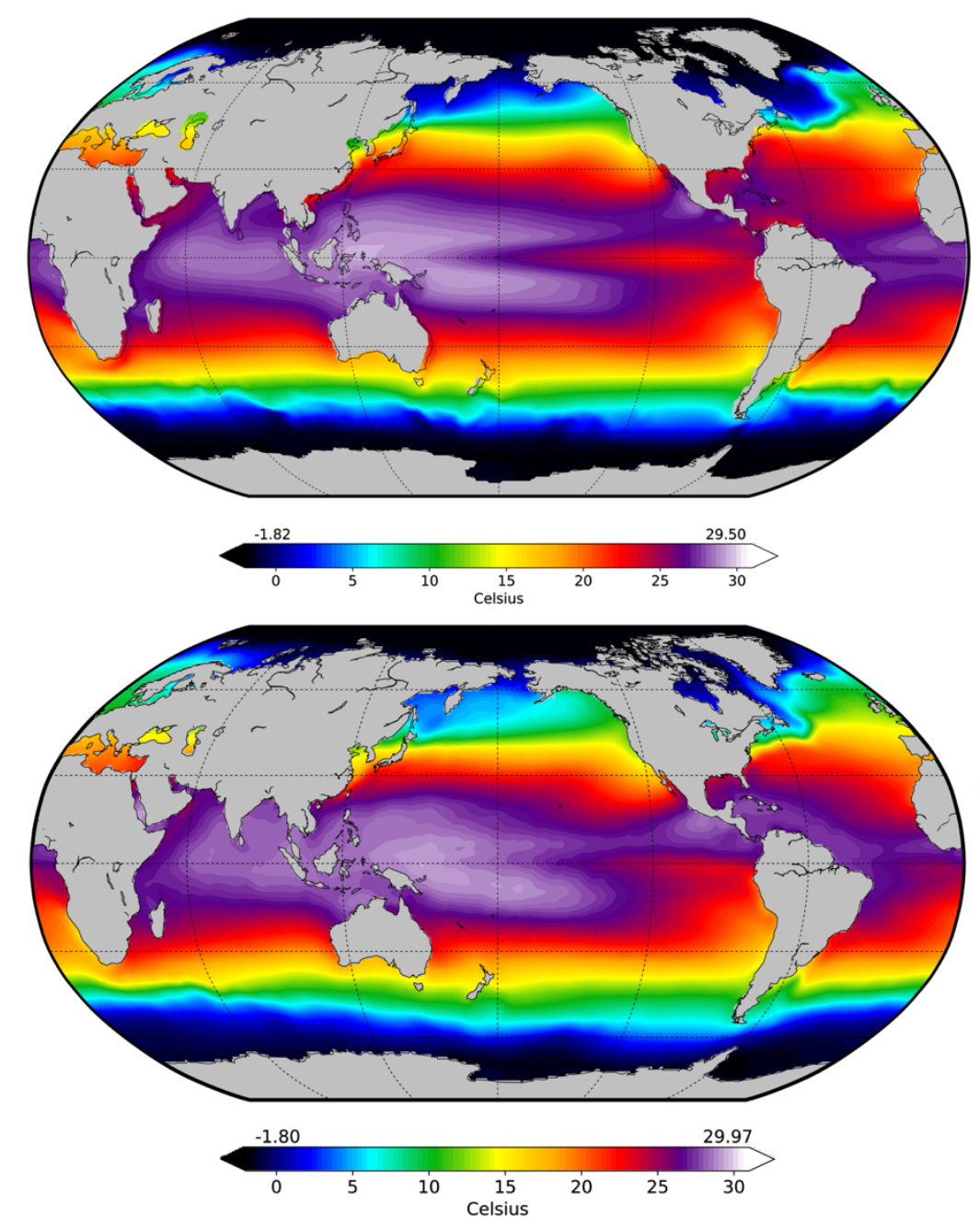

Figure S6. Climatological (years $5131-5160$ ) mean SST in the PI control $E^{280} P$ (top) compared to the mean SST for years 1870 - 1899 from the HadISST dataset (bottom). 

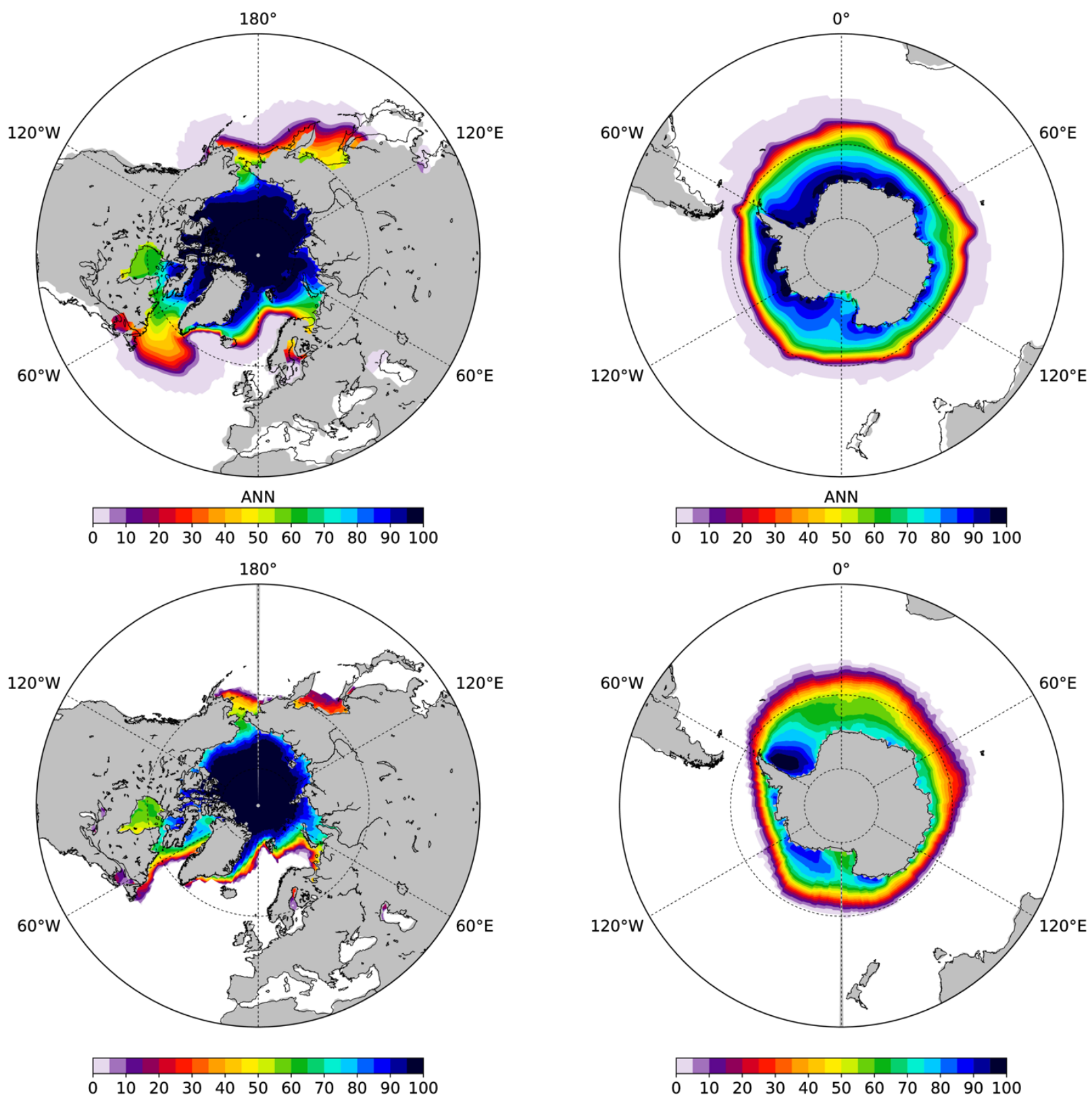

Figure S7. Climatological mean $(5131-5160)$ annual sea ice concentration in the PI control $E^{280} P$ (top row) compared to the mean sea ice concentration for years $1870-1899$ from the HadISST dataset (bottom row). The control simulation is characterized by slightly more expansive sea ice owing to it being an equilibrium climate, and due to the poor nature of observational constraints on sea ice concentrations from this time period. 


\section{Warm Pool}

To determine whether the expanded warm pool is due to the new PlioMIP2 boundary conditions or instead due to the changes to the ocean parameterizations we compare the SST anomaly $\left(E o i^{400} P-E^{280} P\right)$ to the SST anomaly (Eoi ${ }^{400}-$ $\left.E^{280}\right)$. Figure S8 shows that the SST anomaly remains almost identical between these two choices of vastly different depth dependent profiles of the diapycnal diffusivities, $\kappa$. In particular, the region of positive $1-2^{\circ} \mathrm{C}$ SST anomalies in the tropics and the sub tropics, characterizing the expansion of the warm pool in the mid-Pliocene, is present in both anomaly plots. This comparison rules out any doubt that the expansion of the warm pool is the result of the modifications to the boundary conditions rather than from our choice of the $\kappa$ parameterization. Note however, this does not imply that the anomaly between "a Pliocene simulation" and "a PI" would be similar to that shown in Figure S8 for any/all choices of $\kappa$; indeed, for a spatially heterogeneous choice of $\kappa$, such as a tidal mixing scheme, the anomaly would be expected to be quite different in response to the large spatial variations in the strength of $\kappa$. What we have done by utilizing simplified schemes for $\kappa$, is to clearly isolate the impact of the revised boundary conditions from any subtleties associated with choices of $\kappa$. 

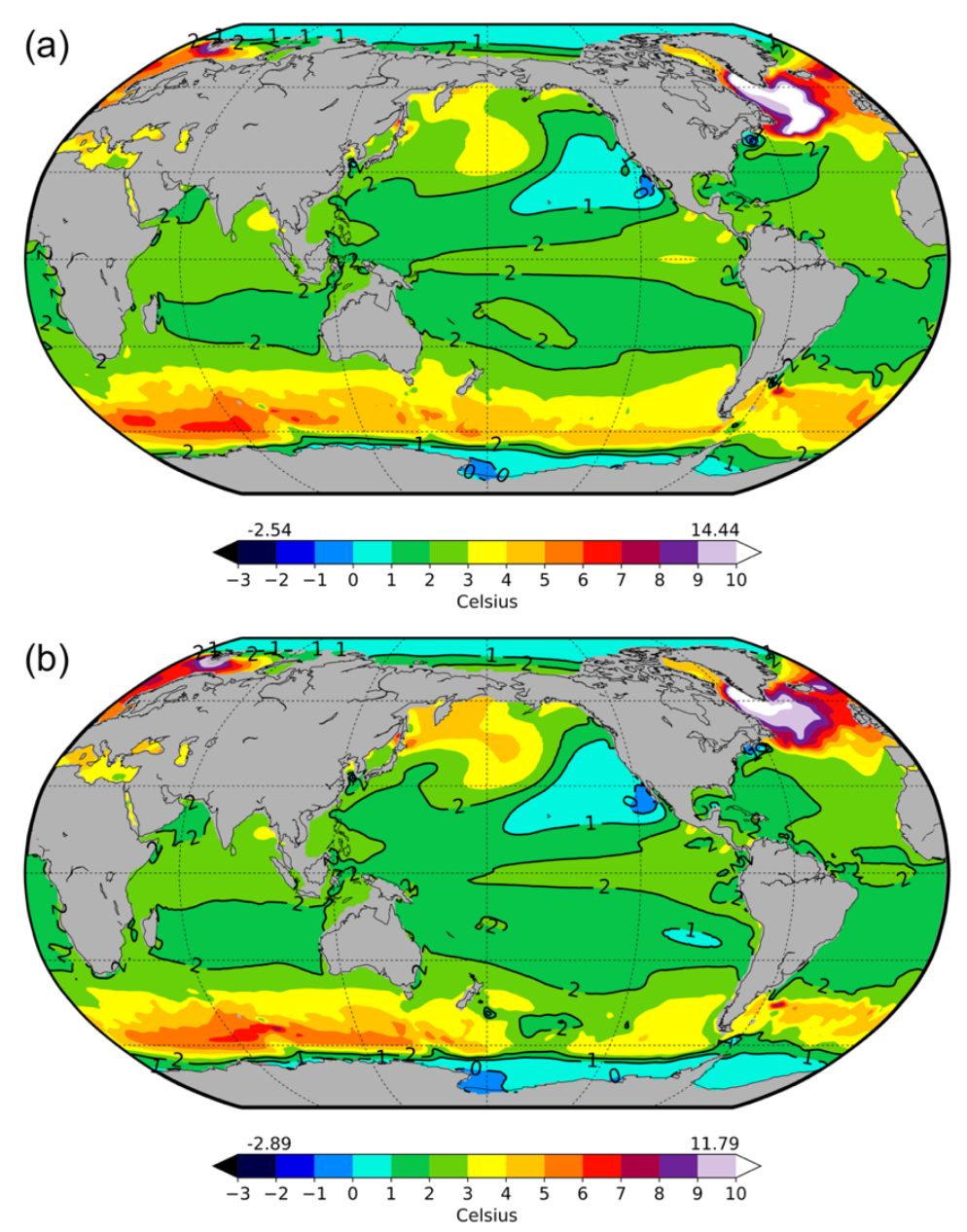

Figure S8. SST anomalies of $400 \mathrm{ppmv}$ Pliocene simulation with respect to PI control. (a) Anomaly with the POP1 variant simulations (i.e. $E o i^{400} P-E^{280} P$ ), (b) anomaly with the constant kappa set of simulations (i.e. $E o i^{400}-E^{280}$ ).

\section{5. mid-Pliocene - PI sea ice anomalies}
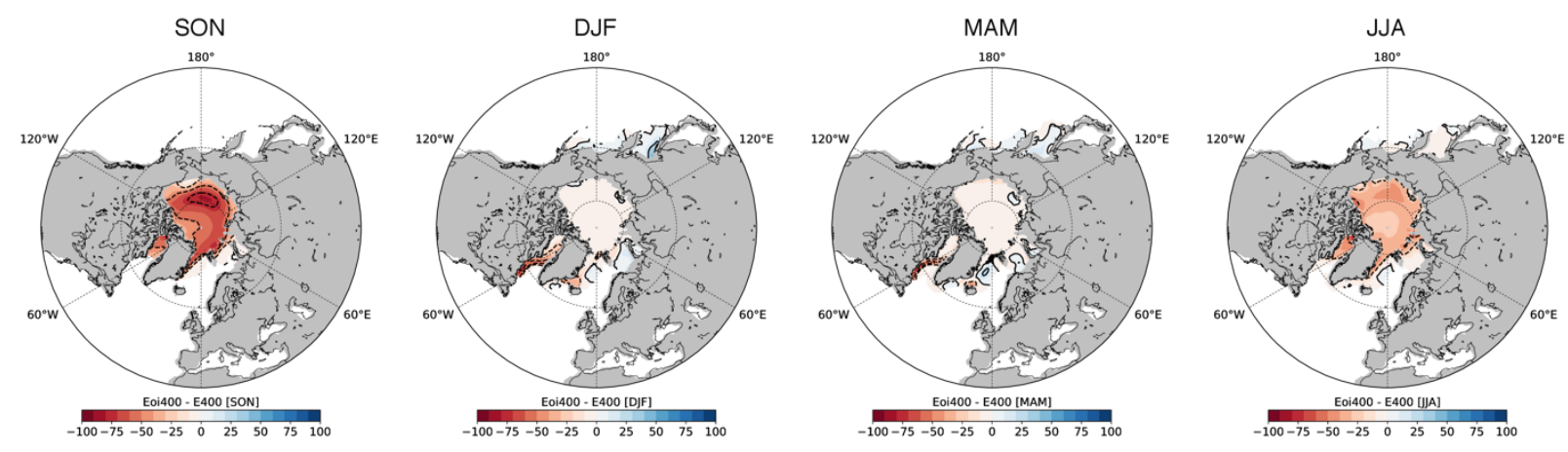

Figure S9. Seasonal sea ice concentration anomalies between the $E_{0 i}{ }^{400} P$ (years $2691-2720$ ) and $E^{280} P$ (years $5131-5160$ ) simulations. 


\section{Mega biomes to PFT mapping}

Mapping between the 9 mega-biome mid-Pliocene vegetation of Salzmann et al. [2008] to CLM4 Plant Functional Types (PFTs) that we have used to initialize the vegetation distribution in our mid-Pliocene simulations.

\begin{tabular}{|l|l|l|}
\hline Mega Biome & $\begin{array}{l}\text { One or more PFTs to } \\
\text { which we map }\end{array}$ & $\begin{array}{l}\text { Fractional projection on } \\
\text { each PFT }\end{array}$ \\
\hline 1 & 5,7 & $0.8,0.2$ \\
\hline 2 & $2,6,8$ & $0.5,0.4,0.1$ \\
\hline 3 & 15,1 & $0.8,0.2$ \\
\hline 4 & 15,1 & $0.8,0.2$ \\
\hline 5 & 1 & 1.0 \\
\hline 6 & 8,14 & $0.8,0.2$ \\
\hline 7 & $3,12,4$ & $0.7,0.25,0.05$ \\
\hline 8 & 13 & 1.0 \\
\hline 9 & 13 & 1.0 \\
\hline
\end{tabular}

\section{References}

Levitus, S. and Boyer, T. P.: World Ocean Atlas, Volume 4: Temperature NOAA Atlas NESDIS 4, U.S. Government Printing Office, 1994.

Rayner, N. A., Parker, D. E., Horton, E. B., Folland, C. K., Alexander, L. V., Rowell, D. P., Kent, E. C., Kaplan, A. (2003) Global analyses of sea surface temperature, sea ice, and night marine air temperature since the late nineteenth century, J. Geophys. Res. Vol. 108, No. D14, 4407 10.1029/2002JD002670

Salzmann, U., Dolan, A. M., Haywood, A. M., Chan, W.-L., Voss, J., Hill, D. J., AbeOuchi, A., Otto-Bliesner, B. L., Bragg, F. J., Chandler, M. A., Contoux, C., Dowsett, H. J., Jost, A., Kamae, Y., Lohmann, G., Lunt, D. J., Pickering, S. J., Pound, M. J., Ramstein, G., Rosenbloom, N. A., Sohl, L. E., Stepanek, C., Ueda, $\mathrm{H}$. and Zhang, Z.: Challenges in quantifying Pliocene terrestrial warming 
revealed by data--model discord, Nature Climate Change, 3(11), 969--974, doi:10.1038/nclimate2008, 2013. 